\title{
The effect of low dose midazolam in addition to ondansetron on post-operative nausea and vomiting in laparoscopic cholecystectomy - a comparative study.
}

*MM Masum-Ul Haque ${ }^{1}$, Montosh K Mondal ${ }^{2}, \mathrm{~S} \mathrm{Afroz}^{3}$, SS Akhter ${ }^{4}$, Abdul Hye ${ }^{5}$, AKM Akhtaruzzaman $^{6}, \mathrm{KM} \mathrm{Iqbal}^{7}$

${ }^{1,3,7}$ Apollo Hospitals, Dhaka, ${ }^{2,5,6}$ Department of Anaesthesia , Analgesia \& Intensive Care Medicine ,Bangabandhu Sheikh Mujib Medical University, Dhaka, ${ }^{4}$ Upazila Health Complex, Nokla, Sherpur

Corresponding author: mmmhaque@yahoo.com

\begin{abstract}
Background Nausea, retching and vomiting are among the most common postoperative complaints. Premedication with low dose midazolam in addition to ondansetron is more effective in controlling postoperative nausea and vomiting.
\end{abstract}

Objectives This study was designed to observe the effect of low dose midazolam 7.5mg in addition to ondansetron $4 \mathrm{mg}$ on postoperative nausea and vomiting in laparoscopic cholecystectomy.

Methods 100 patients of ASA grade I and II, age range 30-50 years and weight 50-70 kg were randomly selected by a blind envelop method. They were equally divided into four groups of 25 patients in group each. Group I received vitamin, Group II ondansetron 8mg, Group III ondansetron 8mg and midazolam $7.5 \mathrm{mg}$ and Group IV ondansetron $4 \mathrm{mg}$ and midazolam $7.5 \mathrm{mg}$ orally one hour before operation. In the recovery room occurrence of nausea and vomiting was assessed for 24 hours.

Results The incidence of nausea was in vitamin Group I 64\%, in ond group II $32 \%$, in ond $_{8}+$ mid $_{7.5}$ group III $24 \%$ and in ond ${ }_{4}+$ mid $_{7.5}$ group IV $24 \%$. The incidence among the groups was highly significant ( $\left.p=0.008\right)$.

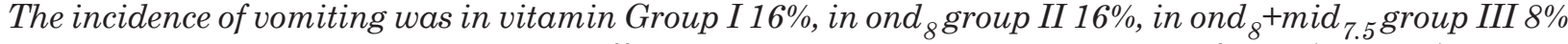
and in ond ${ }_{4}+$ mid $_{7.5}$ group $I V 8 \%$. The difference among the groups were not significant $(p=0.808)$.

Conclusion Low dose midazolam 7.5mg in addition to ondansetron $4 \mathrm{mg}$ is more effective in controlling postoperative nausea and vomiting in laparoscopic cholecystectomy.

Key words Laparoscopic cholecystectomy, PONV, oral ondansetron, midazolam and vitamin.

(JBSA 2011; 24(1): 8-12)

\section{Introduction}

Nausea, retching and vomiting are among the most common postoperative complaints and can occur after general, regional or local anaesthesia ${ }^{1}$. The aetiology of PONV is multifactorial and includes factors related to the characteristics of the patients, the type of surgery, type of anaesthetics and postoperative conditions ${ }^{2}$.

Persistent nausea and vomiting may result in dehydration, electrolyte imbalance and delayed discharge. It may also cause tension on suture lines, venous hypertension and increase bleeding under skin flaps and can expose the subject to an increased risk of pulmonary aspiration of vomitus if airway reflexes are depressed form the residual effects of anaesthetic and analgesic drugs ${ }^{3}$.
Laparoscopic cholecystectomy is associated with a high incidence of (65\%) postoperative nausea and vomiting. Antiemetic prophylaxis may be justified in patients who are at greater risk of developing postoperative nausea and vomiting ${ }^{2}$.

The mechanism of PONV is a complex process that is still not completely understood. It is unlikely that a single drug will ever be totally effective against postoperative nausea and vomiting. The aim in PONV should therefore be to individualize a combination of antiemetics to suit a particular patients. Ondansetron a selective serotonin subtype $3\left(5-\mathrm{HT}_{3}\right)$ antagonist is the new class of antiemetic drug recently introduced into practice. As post operative emesis is a difficult 
multifactorial problem it is best to treat with combination of drugs working via different receptors 6,7 . Low dose midazolam is one of the drugs that can form part of the combination (with ondansetron) requiring for difficult patients.

The mechanism of action of the antiemetic effect of midazolam is not well understood. It has been postulated that midazolam causes a reduction in anxiety and decrease in dopaminergic input to the chemoreceptor trigger zone (CRTZ) . Midazolam may reduce the reuptake of adenosine. This leads to an adenosine mediated reduction in synthesis, release and postsynaptic action of dopamine at the $\mathrm{CRTZ}^{7}$. It may be that Benzodiazepines reduce dopaminergic neuronal activity by binding to the $\mathrm{GABA}_{\mathrm{A}}$ benzodiazepine receptor complex . Midazolam may also reduce 5-HT release by binding to the $\mathrm{GABA}_{\mathrm{A}}$ benzodiazepine receptor complex ${ }^{6}$.

\section{Methods}

This randomized prospective clinical study was carried out in the Department of Anaesthesia, Analgesia and Intensive Care Medicine, Bangabandhu Sheikh Mujib Medical University, Shahbag, Dhaka. The approval of the University Ethical Committee was duly taken before carrying out the study informed consent was taken.

Patients aged between 30 -50 years and weight between $50-70 \mathrm{~kg}$ weight of both sexes ASA Class I and II scheduled for laparoscopic cholecystectomy. Patients with persisting vomiting during the last 24 hours before surgery, antiemetics during the last 24 hours before surgery, expected to have a nasogastric tube after surgery, uncontrolled clinically important neurological, renal, hepatic, cardiovascular, metabolic or endocrine dysfunction, were excluded from this study.

After recruitment 100 patients were randomly divided into four equal groups of 25 patients each. Patients in group I received Vitamin, in Group II

\section{Results}

Table I The age, body weight, sex and ASA grading are presented.

\begin{tabular}{|c|c|c|c|c|c|c|}
\hline & & \multicolumn{4}{|c|}{ Groups } & \multirow[t]{2}{*}{$\mathrm{p}$} \\
\hline & & Vit & $\mathrm{Ond}_{8}$ & $\mathrm{Ond}_{8}+\mathrm{Mid}_{7.5}$ & $\mathrm{Ond}_{4}+\mathrm{Mid}_{7.5}$ & \\
\hline Age (Years) & & $44.04 \pm 16.12$ & $39.16 \pm 14.61$ & $37.04 \pm 9.85$ & $45.2 \pm 14.53$ & 0.129 \\
\hline Body weight (Kg) & & $58.16 \pm 8.9$ & $51.32 \pm 9.54$ & $59.52 \pm 7.37$ & $56.32 \pm 10.16$ & 0.011 \\
\hline \multirow[t]{2}{*}{ Sex } & Male & $5(20 \%)$ & $4(16 \%)$ & $4(16 \%)$ & $8(32 \%)$ & 0.459 \\
\hline & Female & $20(80 \%)$ & $21(84 \%)$ & $21(84 \%)$ & $17(68 \%)$ & \\
\hline \multirow[t]{2}{*}{ ASA } & ASA 1 & $23(92 \%)$ & $22(88 \%)$ & $21(84 \%)$ & $16(64 \%)$ & 0.049 \\
\hline & ASA 2 & $2(8 \%)$ & $3(12 \%)$ & $4(16 \%)$ & $9(36 \%)$ & \\
\hline
\end{tabular}

Values are expressed as Mean \pm SD or in frequencies. Within parenthesis are percentage over column total. Values are regarded as significant if $\mathrm{p}<0.05$. ondansetron $8 \mathrm{mg}$, in group III ondansetron $8 \mathrm{mg}$ and midazolam $7.5 \mathrm{mg}$, in group IV ondansetron $4 \mathrm{mg}$ and midazolam $7.5 \mathrm{mg} 1$ hour before surgery. On arrival of the patients in the operation theatre intravenous line was inserted Before intravenous induction by thiopental sodium $3-5 \mathrm{mg} / \mathrm{kg}$ body weight all patients were pre-oxygenated with 100\% oxygen for 2 minutes after receiving a preinduction dose of fentanyl $1 \mu \mathrm{gm} / \mathrm{kg}$ body weight. Endotracheal intubation was facilitated by succinylcoline $1.5 \mathrm{mg} / \mathrm{kg}$ body weight. Before endotracheal intubations nasogastric suction tube was introduced. Vecuronium $0.1 \mathrm{mg} / \mathrm{kg}$ b.w. was given for muscle relaxation and anaesthesia was maintained with $40 \%$ oxygen, nitrous oxide $60 \%$ and halothane $0.5-1 \%$ and incremental dose of fentanyl (0.3-0.4 mmg/kg body weight) was given if necessary. Intraoperative proper hydration was maintained with normal saline or Hartman's solution. Tracheal extubation was performed after reversal of neuromuscular blocking agent by neostigmine 0.04$0.05 \mathrm{mg} / \mathrm{kg}$ b.w. and atropine $0.02 \mathrm{mg} / \mathrm{kg}$ b.w. Before extubation nasogastric suction tube was removed. In the recovery room pethidine at a dose of $1 \mathrm{mg} / \mathrm{kg}$ b.w. was given intramuscularly in each patient 12 hourly and on demand for analgesia and sedation. The 24 hours study period started upon entry to the recovery room. The haemodynamic parameters were measured preoperatively, then 5 minutes, 30 minutes, 1 hour and 2 hours after induction and during recovery. Postoperatively those were observed at 30 minutes, 1 hour, 2 hours, 4 hours, 8 hours, 16 hours and 24 hours.

The number and time of emetic episodes and antiemetic treatments were recorded. Injection ondansetron $4 \mathrm{mg}$ was used once as the rescue antiemetic. The result was compiled and analyzed statistically using chi-square test and ANOVA test. Results were considered significant if 'p' value is less than 0.05. (CI - 95\%) 
Table II The incidence of nausea in four groups are shown in number and percentage.

\begin{tabular}{lcc}
\hline Groups $(\mathrm{n}=25)$ & \multicolumn{2}{c}{ Nausea } \\
& $\mathrm{N}$ & $(\%)$ \\
\hline Vit & 16 & $(64 \%)$ \\
Ond $_{8}$ & 8 & $(32 \%)$ \\
Ond $_{8}+\mathrm{Mida}_{7.5}$ & 6 & $(24 \%)$ \\
Ond $_{4}+\mathrm{Mida}_{7.5}$ & 6 & $(24 \%)$ \\
Chi-Square & & 11.8 \\
P value & & 0.008 \\
\hline
\end{tabular}

Values are presented as frequency. Within parenthesis are percentages over column total. Analysis was done by chi-square test. Values are regarded as significant if $\mathrm{p}<0.05$.
Table III The incidence of vomiting in four groups are shown in number and percentage.

\begin{tabular}{lcc}
\hline Group & \multicolumn{2}{c}{ Vomiting } \\
& $\mathrm{N}$ & $(\%)$ \\
\hline Vit & 4 & $(16 \%)$ \\
Ond $_{8}$ & 4 & $(16 \%)$ \\
Ond $_{8}+$ Mida $_{7.5}$ & 2 & $(8 \%)$ \\
Ond $_{4}+$ Mida $_{7.5}$ & 2 & $(8 \%)$ \\
Chi-Square & & .97 \\
P value & & 0.808 \\
\hline
\end{tabular}

Values are presented as frequency. Within parenthesis are percentages over column total. Analysis was done by chi-square test. Values are regarded as significant if $\mathrm{p}<0.05$.

Table IV The incidence of rescue antiemitic in four groups are shown in number and percentage

\begin{tabular}{lcc}
\hline Group $(\mathrm{n}=25)$ & $\mathrm{N}$ & $(\%)$ \\
\hline Vitamin & 4 & $(16 \%)$ \\
Ondansetron $(8 \mathrm{mg})$ & 3 & $(12 \%)$ \\
Ondansetron $(8 \mathrm{mg})+$ Midazolam $(7.5 \mathrm{mg})$ & 2 & $(8 \%)$ \\
Ondansetron $(4 \mathrm{mg})+$ Midazolam $(7.5 \mathrm{mg})$ & 2 & $(8 \%)$ \\
$\chi^{2}$ value & & 0.758 \\
$\mathrm{p}$ value & & 0.86 \\
\hline
\end{tabular}

Values are presented as frequency. Within parenthesis are percentages over column total. Analysis was done by chi-square test. Values are regarded as significant if $p<0.05$.

Table $\mathrm{V}$ The scoring of sedation in four groups are shown in number and percentage.

\begin{tabular}{|c|c|c|c|c|c|c|c|c|c|c|c|c|c|c|c|c|c|c|c|c|c|}
\hline \multirow[t]{3}{*}{ Group } & \multicolumn{21}{|c|}{ Sedation score after recovery } \\
\hline & \multicolumn{3}{|c|}{ at $30 \mathrm{~min}$ at } & \multicolumn{3}{|c|}{$60 \mathrm{~min}$} & \multicolumn{3}{|c|}{ at $2 \mathrm{hr}$} & \multicolumn{3}{|c|}{ at $4 \mathrm{hr}$} & \multicolumn{3}{|c|}{ at $8 \mathrm{hr}$} & \multicolumn{3}{|c|}{ at $16 \mathrm{hr}$} & \multicolumn{3}{|c|}{ at $24 \mathrm{hr}$} \\
\hline & 0 & 1 & 2 & 0 & 1 & 2 & 0 & 1 & $\overline{2}$ & 0 & 1 & 2 & 0 & 1 & 2 & 0 & 1 & 2 & 0 & 1 & $\overline{2}$ \\
\hline \multirow{3}{*}{ Vit } & & 24 & 1 & 9 & 15 & 1 & - & 12 & 13 & - & 2 & 23 & 1 & 6 & 18 & - & - & 25 & 25 & - & \\
\hline & 0 & $(96 \%)$ & $(4 \%)$ & $(36 \%)$ & $(60 \%)$ & $(4 \%)$ & & $(48 \%)$ & $(52 \%)$ & & $(8 \%)$ & $(92 \%)$ & $(4 \%)$ & $(24 \%)$ & $(72 \%)$ & & \multicolumn{5}{|c|}{$(100 \%)(100 \%)$} \\
\hline & & 24 & 1 & 4 & 19 & 2 & 1 & 4 & 20 & 1 & 2 & 22 & 7 & 17 & 1 & - & 1 & 24 & 22 & 3 & \\
\hline $\mathrm{Ond}_{8}$ & 0 & $(96 \%)$ & $(4 \%)$ & $(16 \%)$ & $(76 \%)$ & $(8 \%)$ & $(4 \%)$ & $(16 \%)$ & $(80 \%)$ & $(4 \%)$ & $(8 \%)$ & $(88 \%)$ & $(28 \%)$ & $(68 \%)$ & $(4 \%)$ & & $(4 \%)$ & $(96 \%)$ & (88\%) & $(12 \%)$ & \\
\hline $\mathrm{Ond}_{8}+$ & 0 & 17 & 8 & 11 & 14 & - & - & 8 & 17 & - & 3 & 22 & 3 & 20 & 2 & - & 4 & 21 & 24 & 1 & \\
\hline $\operatorname{Mid}_{7.5}$ & & $(68 \%)$ & $(32 \%)$ & $(44 \%)$ & $(56 \%)$ & & & $(32 \%)$ & (68\%) & & $(12 \%)$ & $(88 \%)$ & $(12 \%)$ & $(80 \%)$ & $(8 \%)$ & & $(16 \%)$ & (84\%) & $(96 \%)$ & $(4 \%)$ & \\
\hline $\mathrm{Ond}_{4}+$ & 0 & 21 & 4 & 8 & 17 & - & 1 & 10 & 14 & 1 & 4 & 20 & 1 & 11 & 13 & 1 & 9 & 15 & 23 & 2 & \\
\hline $\operatorname{Mid}_{7.5}$ & & $(84 \%)$ & $(16 \%)$ & $(32 \%)$ & $(68 \%)$ & & $(4 \%)$ & $(40 \%)$ & $(56 \%)$ & $(4 \%)$ & $(16 \%)$ & $(80 \%)$ & $(4 \%)$ & $(44 \%)$ & $(52 \%)$ & $(4 \%)$ & $(36 \%)$ & $(60 \%)$ & $(92 \%)$ & (8\%) & \\
\hline$\chi^{2}$ value & & & 10.963 & & & 7.824 & & & 7.993 & & & 3.218 & & & 41.255 & & & 7.556 & & 3.546 & \\
\hline $\mathrm{p}$ value & & & 0.012 & & & 0.251 & & & 0.239 & & & 0.781 & & & 0.001 & & & 0.056 & & 0.315 & \\
\hline
\end{tabular}

$0=$ Full awake, $1=$ Drowsy, $2=$ Asleep, rousable

Values are presented as frequency. Within parenthesis are percentages over column total. Analysis was done by chi-square test. Values are regarded as significant if $p<0.05$. 


\section{Discussion}

Nausea, retching and vomiting are among the most common postoperative complaints. Factors associated with an increased risk of postoperative emesis include age, gender, obesity, previous history of motion sickness or postoperative vomiting, anxiety, gastroparesis, pain, hypoxia, type of anaesthetic, hypotension, and type and duration of the surgical procedure. Patients undergoing laparoscopic surgery are at high risk for postoperative nausea and vomiting.

Di Florio and Goucke studied the effect of low dose midazolam on postoperative nausea and vomiting 8 . They used injection midazolam $1 \mathrm{mg} / 70 \mathrm{~kg} / \mathrm{hr}$ intravenous infusion in normal saline at the concentration of $10 \mathrm{mg} / 100 \mathrm{ml}(.1 \mathrm{mg} / \mathrm{ml})$ on those patient where PONV were not controlled even after giving the metoclopramide $10 \mathrm{mg}$ as pretrial and prochlorperazine $12.5 \mathrm{mg}$ and droperidol $1.25 \mathrm{mg}$ as antiemetic intravenously. There was no clinically significant difference in sedation score or change in $\mathrm{SpO}_{2}$ in either the saline or midazolam groups, however one patient in each group became confused and disoriented and their infusion were ceased early. Patients in the midazolam group had significantly smaller cumulative nausea scores $(p=0.04)$ and number of vomits $(p=0.02)$. Rescue antiemetics were only required in the placebo group $(p=0.003)$. They concluded that low dose midazolam infusion would be safe and effective in the treatment of resistance PONV.

In our study the incidence of nausea was $64 \%$ in group I, $32 \%$ in group II, $24 \%$ in group III and $24 \%$ in group IV. And the incidence of vomiting was $16 \%$ in group I, $16 \%$ in group II, $8 \%$ in group III and $8 \%$ in group IV.

In comparison to their study we found that, the incidence of nausea and vomiting were equal in group III and group IV. Rescue antiemetics ondansetron $4 \mathrm{mg}$ intravenously were used as a single bolus dose in group I 16\%, group II $12 \%$, group III $8 \%$ and group IV $8 \%$. Here it was also seen that the use of rescue antiemetics were equal in group IV compare to group III. Requirement of antiemetic intravenously could be cause of oral form in our study compare to the continuous infusion in Di Florio and Goucke's study.
In the present study, the difference of sedation scores of the patients in four groups at different time intervals were not significant except at 30 minutes $(\mathrm{p}=0.012)$ and 8 hours after recovery. Probably it was due to the early and late analgesic and sedative properties of pethidine.

To maintain the postoperative analgesia pethidine $1 \mathrm{mg} / \mathrm{kg}$ body wt. was given intramuscularly 12 hourly and on demand. In the present study, it was a great satisfaction that though injection pethidine was given to all patients of four study groups for post operative analgesia and sedation, there were no increase in frequency of nausea and vomiting episodes as its side effects, which were also probably blocked by the combination of ondansetron and midazolam.

In comparison to Di. Florio and Goucke ${ }^{8}$, in the present study, there was no confusion and disorientation of any patient among the four study groups as happened in one patient of each group of them. Probably it was due to oral form rather than the continuous infusion.

So study concluded that Oral premedication with midazolam $7.5 \mathrm{mg}$ in addition to ondansetron $4 \mathrm{mg}$ is more effective as compare to ondansetron alone in controlling postoperative nausea and vomiting in laparoscopic cholecystectomy.

\section{References}

1. Aitkenhead A.R. Postoperative care. In: Alan R. Aitkenhead, David J. Rowbotham, Graham smith. Textbook of Anaesthesia. Fourth edition, London . Churchill Livingstone, Harcourt Publishers Limited 2001 : 541

2. Watcha MF, White PF. Postoperative nausea and vomiting. Its etiology, treatment, and prevention anesthesiology 1992; 77: 162-184

3. Vance JP, Neill RS, Norri SW. The incidence and aetiology of postoperative nausea and vomiting in a plastic surgery unit. British Journal 1992; 26: 336-339

4. Di Florio T. An update on postoperative nausea and vomiting. In: Keneally J. Jones M, eds. Australian Anaesthesia, Australian and New Zealand College of Anaesthetists, Melbourne VIC 1996; 155-159 
5. Di Florio T. The use of midazolam for persistent postoperative nausea and vomiting. Anaesth Intensive Care 1992; 20: 383-386

6. Reid MS Herrera, Marschitz M, Hokfelt T et al. Differential modulation of striatal dopomine release by intranigral injection of gammaaminobutyric acid (GABA) dynorphan $\mathrm{A}$ and substance P. Eur J. Pharmacol 1998; $147-411$
7. Rocke K, Schwore H, Kilbinger H. The pharmacology of 5 -HT release from enterochromaffin cells. In : Reynolds WM, Andrews PLR, Davis CJ, eds. Serotonin and the scientific basis of antiemetic therapy. Oxford Clinical Communications 1995; 84-89

8. Di Florio T. The effect of Midazolam on Persistent Postoperative Nausea and Vomiting. Anaesth Intensive Care 1999; 27 : 38-40 